\title{
Historical water level change of Lake Weishan in East China from 1758-1902 AD: relationship with the flooding of the Yellow River
}

\author{
Jie Fei $\cdot$ Zhong-Ping Lai $\cdot$ Hong-Ming He $\cdot$ \\ Jie Zhou
}

Received: 21 May 2011/Accepted: 14 October 2011/Published online: 8 November 2011

(C) The Author(s) 2011. This article is published with open access at Springerlink.com

\begin{abstract}
In order to understand high-resolution environmental changes, historical water level changes on decadal and centennial scales have been conventionally analyzed employing documentary records and lake sediments. However, annual records are still limited. Here we report the discovery of water level observations (up to monthly) in the historical literature of the Qing Dynasty (1644-1912 AD). We reconstruct the chronologies of annual mean, maximum and minimum water level changes of Lake Weishan from 1758-1902 AD. The chronologies are compared with the precipitation data (dryness/wetness index data) of four stations in the vicinity of Lake Weishan (i.e., Heze, Jinan, Linyi and Xuzhou). We suggest that the annual water level changes are related to the amount of precipitation at the four stations. In addition, the flooding of the Yellow River significantly affects Lake Weishan, always resulting in extremely high annual mean, maximum and minimum water levels in the lake. The flooding in 1871 and $1873 \mathrm{AD}$ even destroyed the banks between Lake Weishan-Zhaoyang-Nanyang and Lake Dushan, thus
\end{abstract}

Handling Editor: Kazunori Akitomo.

J. Fei $(\bowtie) \cdot$ Z.-P. Lai

Key Laboratory of Salt Lake Resources and Chemistry, Qinghai Institute of Salt Lakes, Chinese Academy of Sciences, Xining 810008, China

e-mail: feijie@hku.hk; jiefei@ustc.edu.cn

J. Fei

Department of Geography, University of Hong Kong,

Hong Kong, Hong Kong

H.-M. He · J. Zhou

Institute of Soil and Water Conservation,

Chinese Academy of Sciences and Ministry

of Water Resources, Yangling District 712100, China forming a united lake. In particular, we identify a high water level interval from 1851-1855 AD, just prior to the Yellow River channel change event in 1855 AD.

Keywords Lake Weishan - Historical water level change $\cdot 1758-1902$ AD $\cdot$ The Yellow River

\section{Introduction}

Lake water level changes are effective indicators of regional environmental changes. Most research has focused on the relationship between water level change and climate, in particular precipitation, whereas the effects of the flooding of neighboring rivers have been less investigated (Brooks 1923; Dixey 1924; Dearing 1997; Jones et al. 2007).

Documentary records play an important role in lake water level change research, particularly for the era before modern hydrological observations. Employing documentary records, significant progress has been achieved in understanding the decadal and centennial resolved lake water level changes (Zhang 1981; Fang 1993; Nicholson 1999; Nicholson and Yin 2001). However, documentary records about lake water levels are generally fragmentary and qualitative, and thus hamper the reconstruction of annually resolved historical water level chronology. On the other hand, lake sediments are effective in recording decadal and centennial resolved water level changes, but are not very effective in recording annual water level changes (Dearing 1997; Jones et al. 2007). Occasionally, lengthy and detailed pre-modern lake water level records are discovered, and these records are undoubtedly very valuable (Brooks 1923; Dixey 1924).

Here we report the examination and evaluation of the quasi-monthly water level observations of Lake Weishan 
(China) from 1758-1902 AD. The effects of both precipitation and flooding of the Yellow River on the water level change of Lake Weishan will be analyzed. We hope that our investigation will help better understand the causes of the water level change of Lake Weishan, as well as the flooding history of the Yellow River.

Lake Weishan is a shallow freshwater lake in East China (Figs. 1, 2). The climate in this area is a warm, temperate, semi-humid monsoon type. The annual mean temperature is about $14^{\circ} \mathrm{C}$, and the annual total precipitation is 700-760 mm (Wang and Dou 1998; Shen et al. 2008). Prior to the 1870s, Lake Weishan was actually the southern part of the united Lake Weishan-Zhaoyang-Nanyang (Fig. 2). In the 1870s, Lake Weishan-Zhaoyang-Nanyang merged with Lake Dushan, a lake lying to the northeast (Fig. 2), because of successive floods.

During the Qing Dynasty (1644-1912 AD), there were a few reservoirs on the Grand Canal, and Lake Weishan was possibly the most important one. In order to regulate the water supply, water level observations of the reservoirs on the Grand Canal were officially organized. The data set should be particularly valuable as modern observations did not commence until the mid twentieth century in China. Fei (2009) reported the discovery and preliminary interpretation of water level observations of Lakes Weishan, Zhaoyang and Nanyang in 1814-1902 AD. Here we focus on Lake Weishan, which is blessed with the most detailed water level observations and with the fewest gaps. We reconstructed the water level chronologies of Lake Weishan from 1758-1902 AD and further interpreted the relationship with precipitation and with flooding of the Yellow River.

\section{Methods and results}

The original water level observation reports are scattered throughout the many imperial archives of the Qing Dynasty (1644-1912 AD), which are documented in the First Historical Archives of China (Zhongguo Diyi Lishi Danganguan). The Academy of Water Conservancy and Hydroelectric Power (henceforth AWCHP 1988) made a compilation of the material in the extant imperial archives about the floods in the Huaihe River Basin, including the archives on water level observations of Lake Weishan. We consulted the compilation of the AWCHP (1988) and sorted out all of the observation reports; then the photocopies of the imperial archives were examined so as to make up for omissions and rectify deviations. In addition, four observation reports (one in $1758 \mathrm{AD}$, one in $1773 \mathrm{AD}$ and two in $1774 \mathrm{AD}$ ) were identified in the Continuation of Annals of Water Conservancy (Xu Xingshui Jinjian, Li and Pan 1813). These four reports are not found in the extant imperial archives.

According to the extant archives, the earliest record of the water level dates back to 1746 AD. However, the starting point of our present research was set at $1758 \mathrm{AD}$, as no records can be found for 1747-1757 AD. Monthly observations and reports of the water level of Lake Weishan were commenced in $1814 \mathrm{AD}$ at the decree of Emperor Jiaqing (who reigned from 1796-1820 AD; Li and Pan 1813; AWCHP 1988; Man 2000). The lake water level observations were conducted regularly at the ends of Chinese lunar calendar months. The observation reports were delivered to the emperor monthly ( $\mathrm{Li}$ and Pan 1813; AWCHP 1988). However, the monthly reporting to the
Fig. 1 A map showing the location of Lake Weishan in China

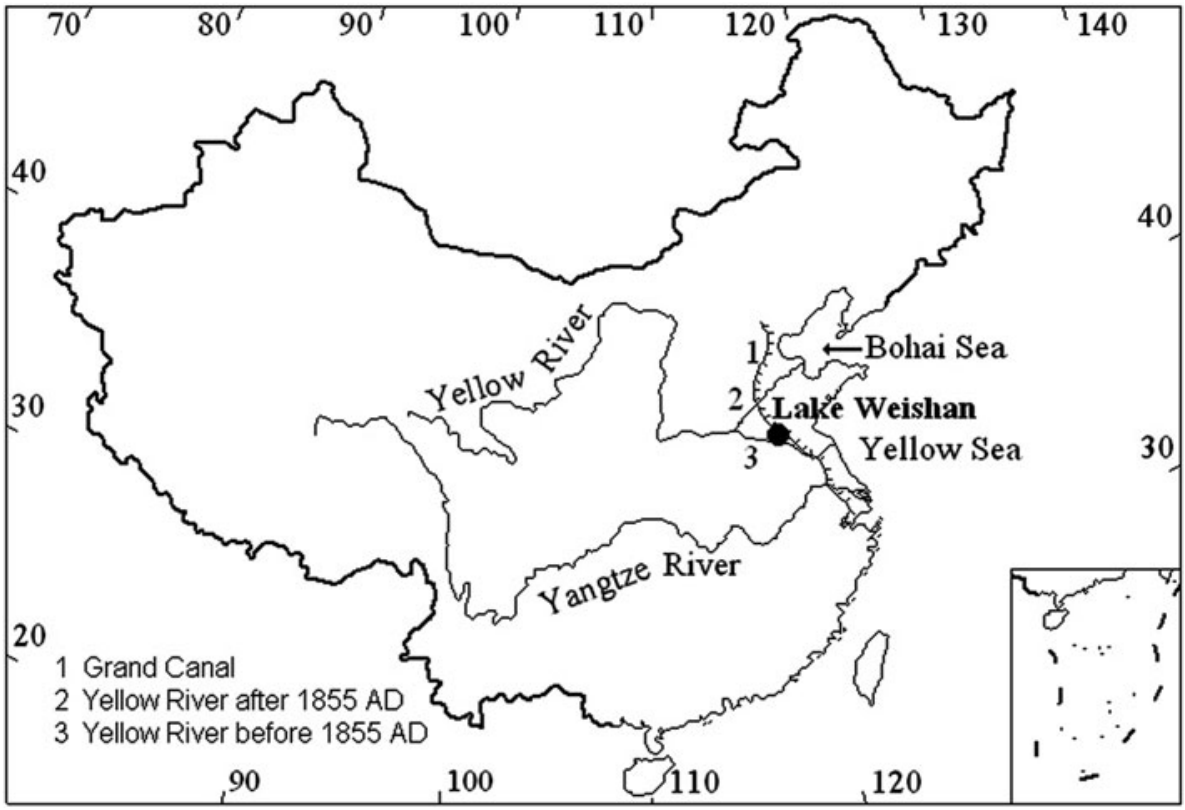


Fig. 2 A map illustrating Lake Weishan and the adjacent area



emperor was canceled in the summer of 1902, and from then on no observation reports can be found in the extant literatures. An example of the original water level observation report is shown in Fig. 3. The chronology of the original water level data is presented in Fig. 4, where the dates are converted into $\mathrm{AD}$ dates, and the original units are converted into the SI unit ' $m$ ' (Fig. 4). The chronologies of the annual mean, maximum and minimum water level changes of Lake Weishan from 1758-1902 AD are also presented in Fig. 4. The reliability of the annual water level change chronologies can be graded into two periods: very accurate from 1814 through 1902 and less accurate from 1758 through 1813.

The Chinese lunar calendar is unique; New Year's Day is generally in January or February of the Gregorian calendar. Most years contain 12 months, but leap years contain 13 months. There are about 37 leap years in each century. Each lunar calendar month contains 29 or 30 days. Conversions of the lunar calendar to the Gregorian calendar can be done using software designed by Academia Sinica, which is available online. ${ }^{1}$

It is worth noting that the water levels were not above sea level, but were the water depths at the observation station, which is located at a sluice called Hukou

\footnotetext{
${ }^{1}$ http://www.sinica.edu.tw/ tdbproj/sinocal/luso.html.
}

Shuangzha (meaning 'a double sluice at the outlet of the lake') (AWCHP 1988, Fig. 2).

During the period from 1758-1813 AD, observations were not conducted on regular dates. All observation records are missing for 9 years: 1778, 1782, 1783, 1787, 1789, 1798, 1799, 1800 and 1801 AD, respectively. For this period, the annual water level was the average of the extant records of a year. A total of 229 records were found, which averages about 5 records per year (excluding the gap years).

For the 1814-1902 AD period, all the observation records are missing for 4 years: 1854, 1862, 1873 and 1877 AD. After excluding the four gap years, the missing points amount to $9.6 \%$ over this period.

The above-mentioned 13 gap years are not interpolated in the chronology. Other missing points that do not cover a whole year are interpolated utilizing the average of neighboring points. For example, the 4th month of the 5th year of the Xianfeng Reign Period (1855 AD) is a missing point. The point is interpolated with the average of the 3rd and 5th months. If a gap is composed of several missing points, the missing points will also be interpolated with the average of the neighboring points. For example, there are three successive missing points in $1844 \mathrm{AD}$, i.e., the 6th, 7 th and 8th months. These points are interpolated with the same value, i.e., the average of the 5th and 9th months. 


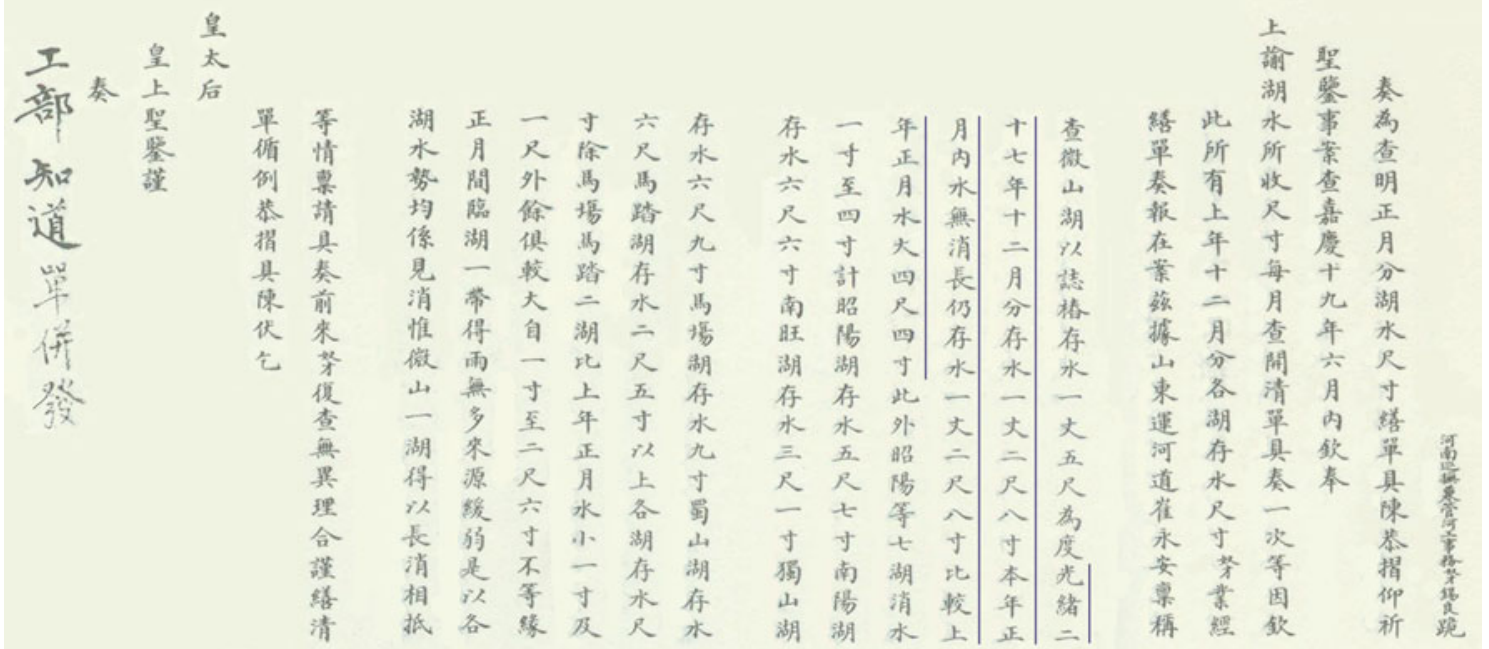

Fig. 3 An example of the original observation report for Lake Weishan, which is the report for the 1st month of the 28th year of the Guangxu Reign Period (8 February-9 March 1902 AD). (The First Historical Archives of China 1996.) It totals 24 columns, and columns 7-10 (from right to left) record the water levels of Lake Weishan: 'It stored 1 zhang, 2 chi and 8 cun of water in the 12th month of the 27th year of the Guangxu Reign Period (10 January-7 February 1902 AD).

In addition, the three missing points in $1851 \mathrm{AD}$, i.e., the 8th month (27 August-24 September), intercalary month (25 September-23 October) and 9th month (24 October-22 November), are interpolated in another way. Because of the high rainfall and flooding of the Yellow River, the water levels in the 8th month and the intercalary month were too high to be measured. The water level dropped gradually in the 9th month, but was still not measurable. In the 10th month, the water level dropped further and enabled a measurement. The water levels of the 8th month, intercalary month and 9th month are filled using the water level of the 10th month, $7.488 \mathrm{~m}$, though the true values should be even higher.

\section{Discussion}

Here we discuss the relationship of the water level change of Lake Weishan with the precipitation and flooding of the Yellow River. In addition, the possible relationship with the Yellow River channel change event in 1855 AD will also be discussed.

No doubt other factors could also affect the water level change. For example, Lake Weishan is a reservoir, and artificial influences should affect water level changes, but no parameters of artificial influence are available. Temperature would be another factor, but meteorological observations in this area and even the neighboring area did not begin until the twentieth century, and the resolution of the temperature-related historical documentary records is 10 years (Ge et al. 2003).
During the 1st month of this year (i.e. the 28th year of the Guangxu Reign Period), the water level did not rise or drop and stayed at 1 zhang, 2 chi and 8 cun. Comparing with the 1st month of the last year (19 February-19 March 1901 AD), the water level is higher by 4 chi and 4 cun.' Here, Zhang ( 1 zhang $=10$ chi $)$, chi and cun $(1$ chi $=10$ cun) was a standard length unit in the Qing Dynasty, and chi refers to yingzao chi, 1 chi $=0.32$ m (AWCHP 1988; Qiu et al. 2001)

\section{Relationship with precipitation}

The relationships between precipitation and the annual lake level are examined using the dryness wetness index (DWI) data set, which comes from the relevant records in the local historical chronicles in China (Central Meteorological Administration of China 1981). The data set has been verified to be accurate and is thus widely used in historical climatology research (Zhang 1988; Zhang and Crowley 1989; Song 2000; Qian et al. 2003; Shen et al. 2007). DWI is a five-grade data set: 5 (very dry), 4 (dry), 3 (normal), 2 (wet) and 1 (very wet) (Fig. 5).

There are four DWI stations in the vicinity of Lake Weishan: Heze, Jinan, Linyi and Xuzhou (Fig. 2). Here we analyze the correlations between annual changes of the water level of Lake Weishan and the DWI of the aforementioned four stations from 1758-1902 (Table 1; Fig. 5).

Of the four stations, the DWI of Heze correlates best with the water level of Lake Weishan, whereas those of Linyi and Jinan rank 2nd and 3rd (Table 1). It is interesting that Xuzhou is the nearest station to Lake Weishan, but the correlation is the least significant one (Table 1; Fig. 5). A possible explanation is that most of the water in Lake Weishan comes from the areas to the north, whereas Xuzhou is located at the south end of the drainage area of Lake Weishan.

On the other hand, the DWI of all four stations correlated significantly with the annual mean, maximum and minimum water level changes of Lake Weishan (Table 1). Among the annual mean, maximum and minimum water 
Fig. 4 The chronology of the raw observational data of Lake Weishan from 1758-1902 AD and the annual mean, maximum and minimum chronologies
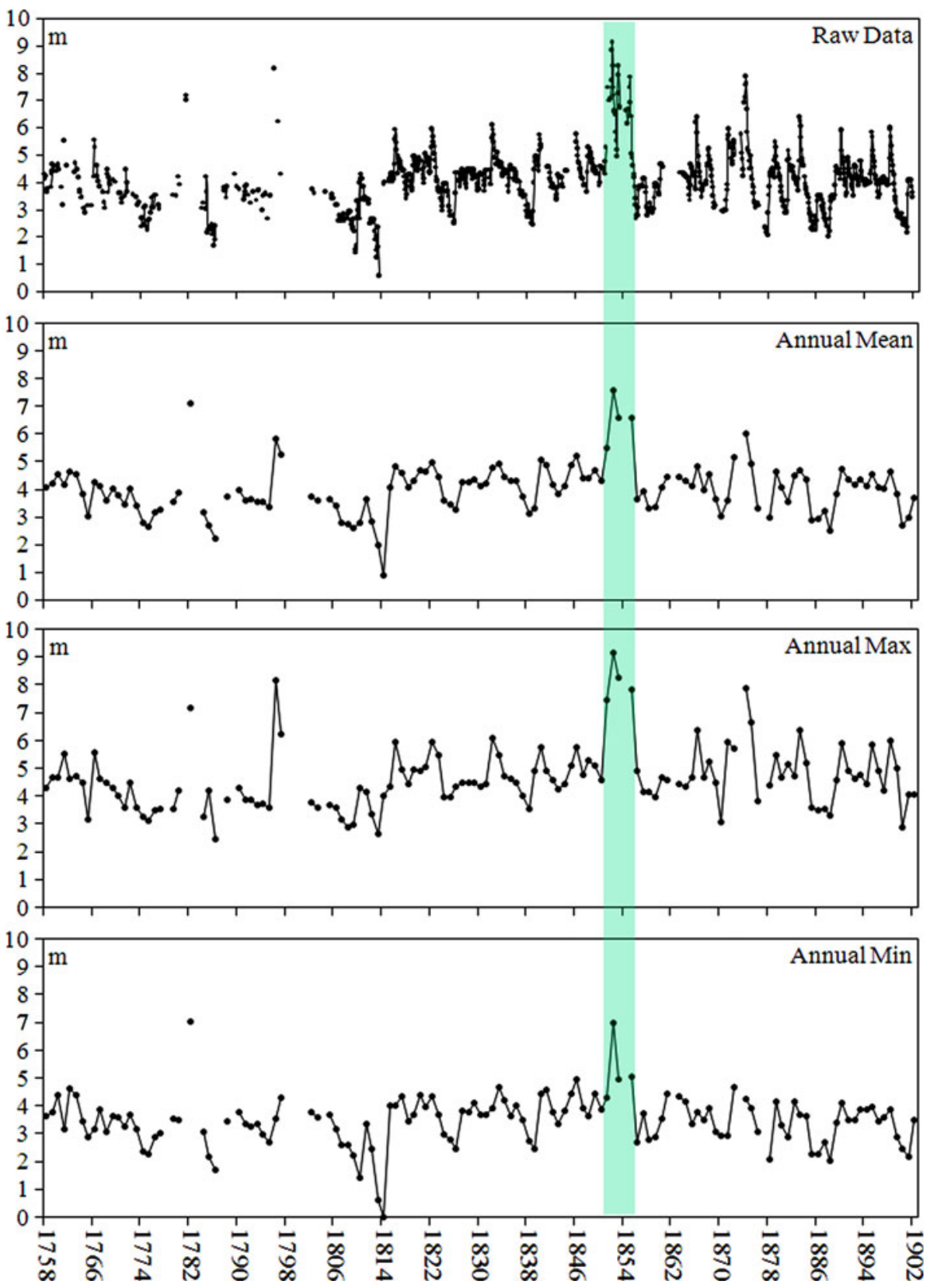

level changes of Lake Weishan, the DWI index correlated best with the annual mean water level change (Table 1).

Generally speaking, the annual mean, maximum and minimum water level changes of Lake Weishan correlated significantly with the precipitation in Heze, Jinan, Linyi and Xuzhou (Table 1).

Relationship with flooding of the Yellow River

The Yellow River flooded frequently in historical times, and occasionally Lake Weishan would be flooded because of its vicinity to the Yellow River. A comparison was made between the years that Lake Weishan was flooded by the
Yellow River and the top 10 years of the highest water levels of Lake Weishan (Table 2).

From 1758-1902 AD, Lake Weishan was flooded by the Yellow River seven times. The flooding of the Yellow River always causes extremely high annual mean, maximum and minimum water levels in the same year and/or the next year in Lake Weishan.

Of the seven Yellow River flooding years, all were followed by the top 10 highest annual mean water level years, six of them were followed by the top 10 highest annual maximum water level years, and four of them were followed by the top 10 highest annual minimum water level years (Table 2). Therefore, the annual mean water level of Lake Weishan 
Fig. 5 The DWI (dryness/ wetness index) chronologies of Heze, Jinan, Linyi and Xuzhou from $1758-1902$ AD. DWI is a five-grade index; 1, 2, 3, 4 and 5 refer to very wet, wet, normal, dry and very dry, respectively
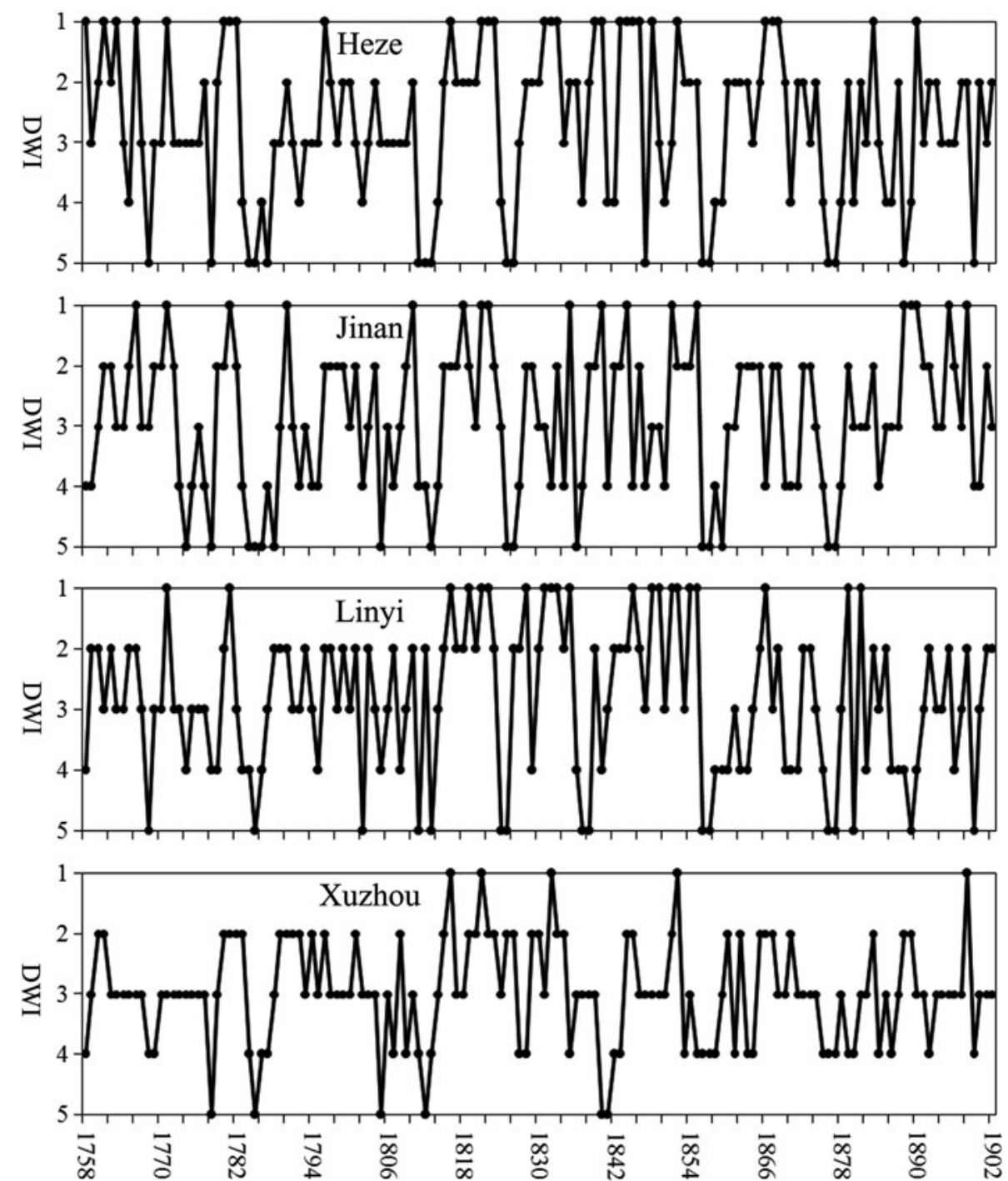

Table 1 The correlations between the annual water level of Lake Weishan and the DWI index changes of Heze, Jinan, Linyi and Xuzhou from $1758-1902$ AD

\begin{tabular}{lllll}
\hline & Heze & Jinan & Linyi & Xuzhou \\
\hline Annual mean water level & $\underline{-0.50}$ & $\frac{-0.42}{-0.39}$ & $\frac{-0.42}{-0.40}$ & $\frac{-0.22}{-0.38}$ \\
Annual maximum water level & $\underline{-0.47}$ & $\underline{-0.36}$ & $\underline{-0.24}$ \\
Annual minimum water level & $\underline{-0.20}$ \\
\hline
\end{tabular}

Underlined figure denotes that the correlation is significant at the 0.01 level, and italicized figure denotes that the correlation is significant at the 0.05 level (two-tailed, $N=132$, i.e., 145 years minus 13 gap years)

corresponded best with the flooding of the Yellow River, whereas that of the annual minimum water level was the least.

Lake Weishan was significantly affected by the flooding of the Yellow River in 1871 and 1873 AD. The flooding corresponded with the top 10 highest water level years of 1872, 1874 and possibly 1875 AD. The bank between Lake
Weishan-Zhaoyang-Nanyang and Lake Dushan was destroyed, thus forming the united Lake Nansi (which means four lakes in the south) (Fig. 2, Wu 1942; AWCHP 1988; Cen 2004). The water level of Lake Weishan was anomalously high in 1872 and 1874, whereas the water level in 1873 remains unknown because of data gaps. 
Table 2 Comparison of the top 10 highest water level years of Lake Weishan and the years that Lake Weishan was flooded by the Yellow River in 1758-1902

Top 10 years of the highest annual mean water level of Lake Weishan Top 10 years of the highest annual maximum water level of Lake Weishan Top 10 years of the highest annual minimum water level of Lake Weishan Years that Lake Weishan was flooded by the Yellow River $\underline{1852}, \underline{1781}, 1855, \underline{1853}, 1874, \underline{1796}, \underline{1851}, 1797,1846,1872$

$\underline{1852}, 1853,1796,1874,1855,1851,1781,1875,1866,1883$

$1781,1852,1855,1846,1853,1833,1872,1762,1841,1861$

$\underline{1781}, \underline{1796}, \underline{1851}, \underline{1852}, \underline{1853}, 1871,1873$

Data for the flooding of the Yellow River are from Cen (2004). The data set was carefully examined and excludes minor floods. Underlined years denote that Lake Weishan was flooded by the Yellow River, and the high water level appeared in the same year. Italicized years denote that Lake Weishan was flooded by the Yellow River, and the high water level appeared in the next year

Possible relationship with the 1855 AD Yellow River channel change event

The successive flooding of the Yellow River in 1851-1853 $\mathrm{AD}$ was followed by an abnormally high water level interval covering 1851-1855 AD (Fig. 4). The water levels in $1851,1852,1853$ and 1855 AD were particularly high. The water level in $1854 \mathrm{AD}$ remains unknown because of data gaps, whereas the DWI scores of Heze, Jinan, Linyi and Xuzhou are 2 (wet), 2 (wet), 1 (very wet) and 3 (normal). Considering the significant correlation between water level and DWI, and high water levels in 1853 and $1855 \mathrm{AD}$, it is reasonable to infer that the water level should also have been high in $1854 \mathrm{AD}$. Therefore, 1851-1855 AD can be identified as a prolonged extremely high water level interval, which is particularly significant in the annual maximum and annual mean water level chronologies. It is noteworthy that this interval is just prior to a great geographic event, i.e., the Yellow River channel change event in $1855 \mathrm{AD}$.

The evolution history of the Yellow River over the past 2,000 years has been complicated but can be divided into three periods: (1) it flowed into the Bohai Sea before the twelfth century; (2) it flowed into the Yellow Sea from the twelfth century to $1855 \mathrm{AD}$; (3) it flowed into the Bohai Sea after 1855 AD (Editorial Committee of the Concise Hydraulic History of the Yellow River 2003; Yao 2003; Cen 2004).

On 1 August 1855 AD, the Yellow River's channel changed significantly and flowed into the Bohai Sea, which was one of the greatest geographical events in the history of China (Figs. 1, 2). The cause of this event is commonly attributed to the high rainfall in late July in $1855 \mathrm{AD}$ in the Yellow River Basin and the problems with the Yellow River's embankments (The Yellow River Conservancy Commission 2003; Cen 2004). The discovery of the existence of this high water level interval in Lake Weishan is helpful to better understand the hydrological background of this great geographical event on an annual time scale.

\section{Conclusion}

In summary, water level observations of Lake Weishan during the Qing Dynasty (1644-1912 AD) were examined according to the extant historical archives. The chronologies of the annual mean, maximum and minimum water level changes of the lake from 1758-1902 AD were reconstructed.

The chronologies are compared with the precipitation data (dryness/wetness index data) of four stations in the vicinity of Lake Weishan (i.e., Heze, Jinan, Linyi and Xuzhou). We suggest that there is a significant positive correlation ( $\alpha=0.05$, two-tailed) between the annual water level changes of Lake Weishan and the precipitation at all four stations in 1758-1902 AD.

Lake Weishan was flooded by the Yellow River a total of 7 years from 1758-1902 AD. The effects of the flooding of the Yellow River on Lake Weishan are very significant. It always results in extremely high annual mean, maximum and minimum water levels in the lake. In particular, the flooding in 1871 and $1873 \mathrm{AD}$ destroyed the banks between Lake Weishan-Zhaoyang-Nanyang and Lake Dushan, thus forming the united Lake Nansi (which means four lakes in the south).

We identified a high water level interval covering 1851-1855 AD, which should be helpful to better understand the hydrological background of a great geographic event on an annual time scale, that is, the channel change of the Yellow River in 1855 AD.

Acknowledgments We wish to thank Dr. Pinas L. Lucien for the helpful suggestions. This research was supported by the One Hundred Talent Project of the Chinese Academy of Sciences (Granted to Z.P. Lai and H.M. He), the China Geological Survey (grant no. 1212011120046) and the National Natural Science Foundation of China (grant no. 41072137).

Open Access This article is distributed under the terms of the Creative Commons Attribution Noncommercial License which permits any noncommercial use, distribution, and reproduction in any medium, provided the original author(s) and source are credited. 


\section{References}

Academy of Water Conservancy and Hydroelectric Power (AWCHP) (1988) Historical flood archive material in the Huaihe River Basin during the Qing Dynasty. The Chinese Press (Zhonghua Shuju), Beijing, pp 1-1075 (in Chinese)

Brooks CEP (1923) Variations in the level of Lake George, Australia. Nature 112:918

Cen Z (2004) The evolution history of the Yellow River. The Zhonghua Book Co., Beijing, pp 554-660 (in Chinese)

Central Meteorological Administration of China (1981) Yearly charts of dryness/wetness in China for the last 500-year period. SinoMaps Press, Beijing (in Chinese)

Dearing JA (1997) Sedimentary indicators of lake-level changes in the humid temperate zone: a critical review. J Paleolimnol 18:1-14

Dixey F (1924) Lake level in relation to rainfall and sunspots. Nature 114:659-661

Editorial Committee of the Concise Hydraulic History of the Yellow River (2003) Concise hydraulic history of the Yellow River. The Yellow River Hydraulic Press, China, pp 1-433 (in Chinese)

Fang J (1993) Lake evolution during the last 3000 years in China and its implications for environmental change. Quat Res 39:175-185

Fei J (2009) Water-level observations of Lake Weishan-ZhaoyangNanyang in China over 1814-1902 AD. Lake Reserv Manag 25(2):131-135

Ge Q, Zheng J, Fang X, Man Z, Zhang X, Zhang P, Wang W-C (2003) Winter half-year temperature reconstruction for the middle and lower reaches of the Yellow River and Yangtze River, China, during the past 2000 years. Holocene 13:933-940

Jones RT, Jordan JT, Edwards ME, Yu G, Ke X, Magee J, Vassiljev J, Shuman B, Finney B, Metcalfe S, Magny M (2007) Lake level studies. Encycl Quat Sci 1319-1399. doi:10.1016/B0-44452747-8/00166-6

Li S, Pan X (1813) Continuation of annals of water conservancy $(X u$ Xingshui Jinjian), vol 69, 90, 111, 123. Published in 1970 by Wenhai Press, Taipei (in Chinese)

Man Z (2000) A review on the historical material series flood archives of Qing Dynasty. Hist Geogr 16:335-346 (in Chinese)

Nicholson SE (1999) Historical and modern fluctuations of lakes Tanganyika and Rukwa and their relationship to rainfall variability. Clim Change 41:53-71
Nicholson SE, Yin X (2001) Rainfall conditions in equatorial East Africa during the 19th century as inferred from the record of Lake Victoria. Clim Change 48:387-398

Qian W, Chen D, Zhu Y, Shen HY (2003) Temporal and spatial variability of dryness/wetness in China during the last 530 years. Theor Appl Climatol 76:13-29

Qiu G, Qiu L, Yang P (2001) History of science and technology in China: length, capacity and weight measures. Science Press, Beijing, pp 421-425 (in Chinese)

Shen C, Wang W-C, Hao Z, Gong W (2007) Exceptional drought events over eastern China during the last five centuries. Clim Change 85:453-471

Shen J, Zhang ZL, Yang LY, Sun QY (2008) Lake Nansi: environment and resource research. Seismology Press, Beijing, pp 6-20 (in Chinese)

Song J (2000) Changes in dryness/wetness in China during the last 529 years. Int J Climatol 20:1003-1015

The First Historical Archives of China (1996) Memorials to the throne with the Emperor's comments during the Guangxu Reign Period, vol 101. Zhonghua Book Company, Beijing, p 460

The Yellow River Conservancy Commission (2003) A concise history of the conservancy of the Yellow River. The Yellow River Conservancy Press, Zhengzhou (in Chinese)

Wang S, Dou H (1998) Encyclopedia of the lakes in China. Science Press, Beijing, pp 301-304 (in Chinese)

Wu T (1942) Re-continuation of annals of water conservancy (Zaixu Xingshui Jinjian), vol 91, 92, 100, 101. Published in 1970, Wenhai Press, Taipei (in Chinese)

Yao H (2003) Research on the hydraulic history of the Yellow River. The Yellow River Hydraulic Press, China, pp 1-604 (in Chinese)

Zhang X (1981) The historical process of the evolution of Lake Tungting. Hist Geogr 1:99-116 (in Chinese)

Zhang D (1988) The method for reconstruction of the dryness/wetness series in China for the last 500 years and its reliability. In: Zhang $\mathrm{J}$ (ed) The reconstruction of climate in china for historical times. Science Press, Beijing, pp 18-31 (in Chinese)

Zhang J, Crowley TJ (1989) Historical climate records in China and reconstruction of past climates (1470-1970). J Climatol 2:833-849 